\title{
Equal value: A Swedish school implementing the Convention on the Rights of the Child
}

\section{Pia Sandström}

School Welfare Officer, pia.sandstrom@harnosand.se

Solenskolan Härnösands kommun

Sweden March 2009

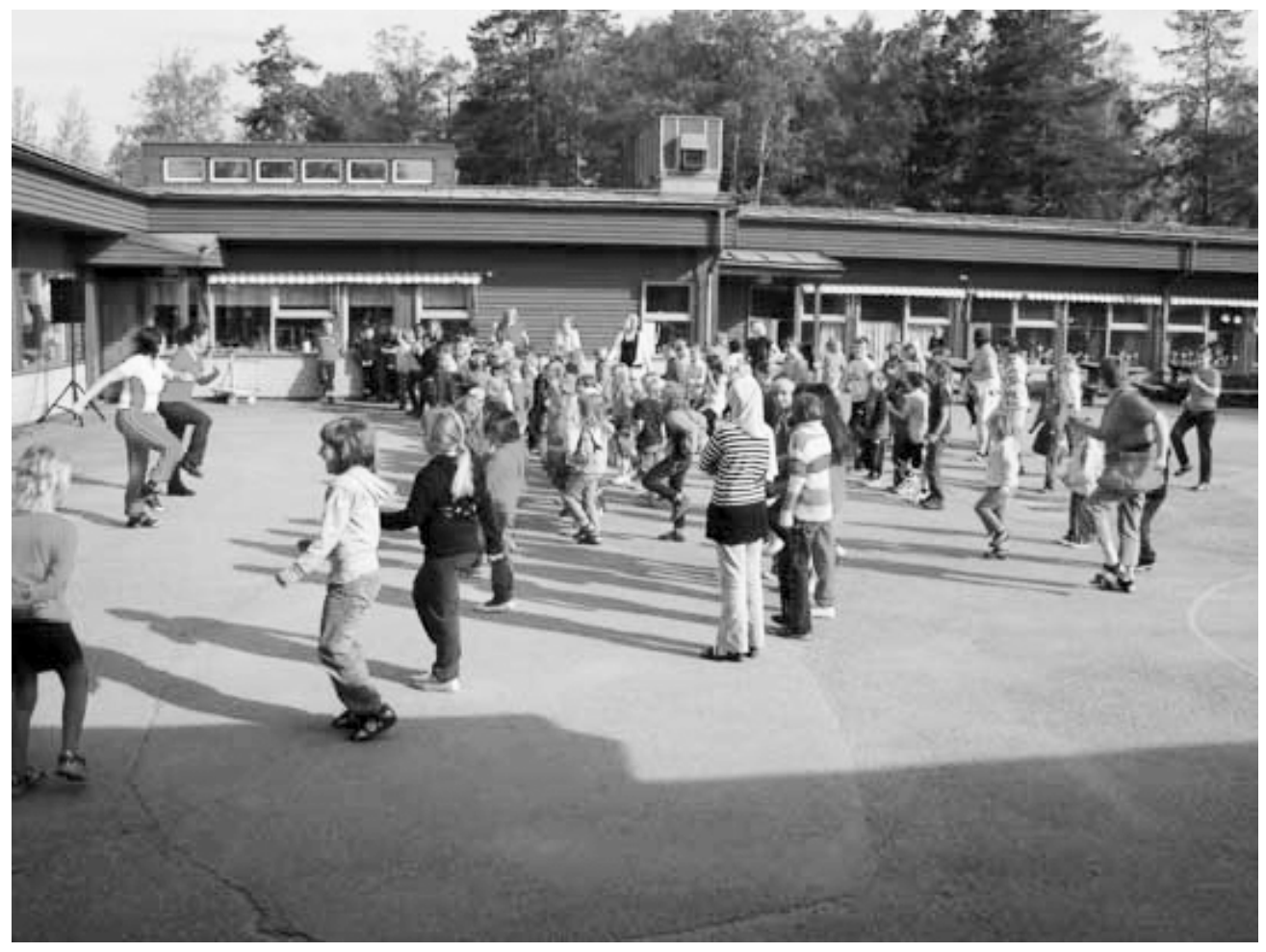

\section{Abstract}

When Solenskolan in Härnösand, Sweden, was built in 1982, the idea was to make room for all different kinds of children. Today the school extends from kindergarten, elementary school to ninth grade, special school and international class. The various forms of schooling coexist under the same roof and management. They collaborate across borders and the school has become a place which suits everyone. The school has long worked systematically to ensure equal value for all and used different strategies. The Swedish school authorities have designated Solenskolan as the 2008 school of equal value. The jury's reasoning is that 
the school is working to improve all children's participation and influence in the school's everyday life. Work is well founded in the Convention on the Rights of the Child's four key pillars. The school has a clear vision where concepts such as knowledge, security, influence and responsibility are demonstrated. Student empowerment and the needs of the child are held as fundamental in all contexts.

The municipality's equal treatment plan is an important tool in the quest to create a school where all can be equally involved. The plan prescribes how schools should interact with children, parents and other stakeholders in the community. At Solenskolan extensive work has been done to develop the influence and participation of children with disabilities or other issues. The school has chosen diversity as its identity. It is seen as a great opportunity to support learning and participation for all children. Diversities are seen as enriching, and this influence makes us prepared for the future.

\section{Introduction}

This article is a presentation of how a Swedish school is working with children's rights and diversity. It is based on a paper the author presented at the New Zealand International School Social Workers conference in the spring of 2009. In Sweden a School Welfare Officer is someone who has counselling tasks with children and students as well as wider perspective on preventive health work. School Welfare Officers are part of the educational team and work with the student's overall social, emotional, behavioural and adaptive functioning at school. Focus is on social problems and processes of change. The school communities employ the School Welfare Officers.

\section{A school of diversity}

Solenskolan was awarded the 2008 prize for school of equal value by Swedish School Authorities. The jury's explanation was as follows:

Solenskolan, preschool till grade nine, in Härnösand is a good example of an inclusive school that works to increase students' participation in school everyday.

The school was nominated for the prize on the following grounds:

Solenskolan is a good example of a school that aims to raise all students' participation and influence in the school on the basis of each student's individual circumstances. The school has long worked systematically for all students to have equal value and for different strategies to be used according to their needs. Work is well founded in the United Nations International declaration on the Rights of the Child. The school has a clear vision and business side, where concepts such as knowledge, security, power and responsibility are foundational. The school describes diversity as its identity - 'We are diverse and equal'.

The school's work for diversity is based on the four pillars of the children's convention, namely:

- All children have the same rights, 
- The child's best interests to be taken into account in any decisions,

- All children have the right to life and development,

- Every child has the right to have their say and have it respected.

This is the basis of diversity work that pervades school activities.

The school in its application for the award described the following basic guiding principles:

\section{The school is actively working to increase the participation of all pupils in the local school culture, learning environment and social life.}

There is a long tradition at our school in terms of all student groups' participation in school activities. Even before the school was built there was active cooperation with concerned students and teachers for the coming integration of the then special school in the newly built school so that it would be a great success. The basic idea was that everyone is equal. It was the autumn of 1981 and the school opened in autumn 1982. The goal was to:

- be together,

- develop together,

- experience and do things together.

In making its award to the school, the jury has weighed in their decision to include that the school extends from kindergarten and elementary school grades to ninth grade, special school and international class even if the school itself does not make the division, but describes itself as 'a place which suits everyone'.

Solenskolan was the first school in Härnösand that was adjusted to the diversified needs of its users. The school opened in the autumn of 1982. Now students with different needs study together in the same building.

In the spring of 1983, students from special school and primary school went together on a camp for three days. Teachers participating on the camp expressed among other things the following:

- All are equally important regardless of where they were born.

- Increased awareness of being good at different things.

- Special school students were more willing to partake in drama and it served as an inspiration to the others.

- Students played spontaneously together during breaks.

Parents from the special school and primary school expressed among other things the following:

- Children seemed to have made more friends.

- Increased awareness that we are all the same but different.

- Increased awareness of the strengths of being different.

From these landmark moments, the school has continued its quest to be an inclusive school. At the present time, the school has students with severe disabilities, students at special 
school, students in primary schools, and a large number of students from other countries. The age span ranges from 6-15.

All classes have representatives in the traditional assembly with council. In class all students are involved with representatives regardless of disability or ethnicity. All dare be heard. On many occasions students with disabilities have contributed proposals which have led to change and development.

We try to always think new and make new. During the spring semester of 2008, therefore, our school chose to participate in student empowerment projects, still underway. The launch consisted of raising the awareness of what we already do, then it is supposed to go further and disseminate knowledge through the project. This has been done through various meetings, discussions, virtual bulletin boards, and exchanges with other schools. The project is led by Linda Eriksson, a development teacher at the Mid Sweden University (www.miun. se). In terms of content, the project aims to develop the knowledge of how student empowerment (all students) can be a real target as well as resources in school and developing the school's democracy and knowledge of the mission.

\section{The school is working actively to build the school activities so as to meet the different needs of students.}

All school students are assessed on their own merits, in the majority of school activities. The school's approach suits all students regardless of disability or origin. For example, when the whole school sings and plays together, students with disabilities attend as often as other students. The most appreciated feature at similar gatherings is our wheelchair dance that is inspiring to everyone. It is often requested. Other activities are sports days, school closings, school jogging and more.

There is a close cooperation between the various forms of schooling. No sharp boundaries exist. Students can move between schools of different kinds, depending on what the need is at that time. Great flexibility exists and we have a natural and obvious cooperation. For example, students from the special school have their lessons in English, together with a group of children in compulsory school, if it is the best for the student. Basic school students participate each week in the special school music education and more.

\section{Solenschool sings:}

At semester closing and start-up, Christmas, Easter and a few other times, the whole school gathers in the gym or schoolyard for the joint singing time, including student performances.

\section{The school is actively working to develop education for all students and their full partici- pation.}

Influence and participation is a human right and the school also has much experience through hard work based on the convention. Diversity is our strength. The student empowerment project also belongs under this heading, as participation provides greater motivation for learning. Scheduled time and support of adults is given for counsel in the classes and conferencing among students. All students also participate in Friends, an organisation founded in 1997 to help schools set up a plan of action against bullying. They work with helping pupils to speak up against meanness and injustice, to make them believe in themselves and to respect and care for each other. In the beginning the school trains the staff. Step two is 
short and forceful information for all the students. The purpose is to raise awareness and engagement against bullying and abusive behaviour. As a student, one knows what the atmosphere and groupings are like in the class. For that reason, two pupils from every class are elected to be Friends-reps by their classmates. They will look at problems in their class together when they have a companion facilitator. We have something called Sweet and Salt (sour) where the students, along with an adult, appoint a friend of the week. This is further announced in assembly, so that everyone in the school can hear who has received this award. Each student receives a diploma.

Staff from the school work on the projects 'The capable child' and 'Forward'. These emphasise the importance of a good learning environment, where the adults are good role models and adults welcoming each other is just as important as the meeting between adultchild and child-child. We need to actively examine our approach.

\section{The school is actively working to develop and make a good school for both pupils and staff.}

This year we have an extra focus on the teacher's role. It involves lectures by Leif Strandberg and John Steinberg on how the social interactions can find the nearest development zone for every individual. All teachers also read the book Leadership in the classroom and there are team discussions. The literature notes the importance of treatment in the classroom, both physically and mentally, as well as the need to understand the factors that involve successful methods, such as clear rules of the game and methods that influence instead of power approaches. Both pupils and staff will benefit from this approach. Our annual evaluations (SOC) 3 help us make visible what we are good at and to see what needs improving. Everything is entered in our goals for the following year. An important goal is that the school/preschool actively take advantage of the opportunities that our business gives us in terms of diversity. We are equally diverse or different. The teachers also all meet frequently in regular mixed group meetings called 'Red thread'. These meetings are primarily for learning and reflection. This is a good forum to discuss aspects of equal value.

One important tool is the individual development plan. The plan must be forward looking and support the work of the student's continued development in a concrete way. The plan should include short-term objectives that are achievable, and that students themselves have the ability to assess whether he/ she has achieved. The targets are to be both educational and social.

\section{The school is working for diversity which is seen as a rich opportunity to support learn- ing and inclusion for all.}

Friends is a nonprofit organisation without government grants. With other Friends-reps and the adult team they take measures to support learning and inclusion for all.

An evaluation is done every year, including job satisfaction in a school survey (grade 1-4) and Sense of Coherence survey from the health schools (grade 5-9). The evaluation also includes an annual survey of parents' experience of working with the business. To develop the school everyday from a salutogenic perspective means that the school evolves in the direction of Antonowsky's 'Sense of Coherence' (SoC) and its three components: comprehension-manageability-validity. This involves strategies to strengthen factors such as relationships, comfort, security, accountability, participation, self-confidence, job satisfaction, 
meaningful physical activity, etc, synthesise findings on the salutogenic concept, SOC, and its correlation with Quality of Life (QoL). The staff also answer the survey.

To update the diversity, this work continuously develops in all subjects and is part of student's choice, open-air days and different thematic works. This year our school has chosen to work with a special theme, communication. The purpose of that work thematically is to: learn to understand; reconcile feelings, knowledge and imagination; and create a learning environment where the goal is that students learn through play, active participation, cooperation and curiosity. The aim is also to work actively for a whole school in the area, where the older students teach the younger and where diversity is seen as enriching. The focus of the theme has been on knowledge and student empowerment (all pupils). Each unit is working on ways that suit their group of students. Every team uses each other's skills. Education is organised in teams and we are working in mixed groups without age and grade restrictions. The sense is: The more we value and appreciate each other, the better each one will be.

\section{The school shows in its activities that all students and all staff are equal.}

Our business concept is based on four pillars: knowledge, security, influence and responsibility-health. Based on these values we have formulated a vision: each unit creates a clear identity, which is part of the resources we have for achieving the objectives. An identity consists of the nature of an entity's content, such as values, attitudes, educational and more.

Our talks, in large groups and small, are often about the fact that we are different but equal. The school is working actively to constantly review operations to improve the visibility of standards and eliminate obstacles to achievement. In our business, we see children, students and staff diversity as an asset. With the concept of diversity, we mean a dynamic use of individuals' skills and resources regardless of background factors such as gender, ethnicity, education, age and disability. Diversity, we think, is our identity and that makes us well prepared for the future.

The school has this year opted to work around the common theme of communication. We work with the theme from kindergarten to grade nine. Every unit and each team work in different ways that suits their children or students. Each team uses each other's skills. Common to the work is that it unites past, present and future, and that it is about our culture and other cultures in a global perspective. The essence of the work is to provide children/students knowledge of the outside world and to give them the courage and will to improve it.

\section{Long-term goals}

\section{Knowledge}

All students in both primary and secondary schools must achieve the minimum qualifications in all subjects. All students who leave the school have the social skills needed to succeed in life. All employees experience that they have equal value and feel they have a manager that is a good leader.

\section{Influence and responsibility}

All children and students take responsibility for and involvement in their own learning. 
All children and students feel that they have influence on the activities. Home and school take a common responsibility for the child/student's development and learning. All parents receive the information they need. All parents feel involved in their children's learning. All employees understand the meaning of their mission and feel involved in the development and the work of health. All activities are marked by a clear health focus.

School activities are in constant development. The basis of the work is also the municipality's plan for equal treatment. Here follows a presentation of some parts of the plan relating to the work of equal value. The contents have been selected on the basis of their relevance for the promotion of work of equal value.

\section{Equal treatment plan}

In April 2006, a new law came into force, whose purpose is to promote children's and students' equal rights and to combat discrimination on the basis of gender, ethnicity, religion or other belief, sexual orientation or disability. The law discourages other degrading treatment. The main reason is that discrimination, harassment and degrading treatment occur where there is a lack of good social relations, security and respect for others' privacy. The physical environment and lack of participation may also be contributing causes. In schools that are successful in their work there are components such as clear leadership, staff with broad commitment and students involved in the process important for the business. In order to reach the curriculum requirement that 'no one shall be subjected to school bullying' several strategies are necessary. We must, and will, attach great importance to the work of values that form the basis for the work of preschool and school.

In addition to Swedish law, the United Nations Convention on the Rights of the Child provides the curriculum to the school to work for equality. Unique to Sweden is the Law on Safety and Health at Work which includes all children and students. Student advocates will be appointed from year seven and above. They should have relevant expertise in the field. Students can rely on the law in event of threats, violence and harassment. It is important that both the preschool and school report statistics on the number of injuries as well as physical, mental, and the number of children/students who are exposed to threats, violence or bullying. This is information that should be included in the quality of financial statements to school authorities.

School management in Härnösands municipality has prepared guidelines on how the local treatment plan should look. It is the headmaster's responsibility that the local treatment plan is established and that all employees, students and parents are familiar with the plan. The headmaster is also responsible for ensuring the plan is complied with and that work continuously will be monitored and evaluated.

\section{Organisation}

Each organisation, each school unit, must have a student health team. The team will promote, support and monitor the health for all students within the organisation. The teams must meet regularly during the school year.

Each unit will in their local plan describe how to organise efforts to combat degrading treatment. Vulnerable students often do not know where to turn for help. A school must 
have several adults who have a special responsibility to listen and help students to move on, and to respond and put an end to degrading treatment. It may be in the form of an antibullying team. The team intervenes directly in acute bullying cases. As soon as someone hears of or suspects that bullying is going on at the school they will make contact with the team. A school can choose to have support comrades or similar which helps adults to see and hear what happens. We know it is when we do not see that children are vulnerable. Therefore, each school should have a plan for supervision during the breaks. Each school informs students and parents in writing about who is working on these issues and where these people can be reached. Information should always be found on the web.

\section{Common values}

Common values to work out and continuous maintainance of the value system is important in all groups. When we do not have a common value, we can see the consequences; selfish behavior, alienation, disloyal behaviour, abuse and violence. History teaches us that a value system, based on equality must constantly be on the agenda. The basic idea of a democracy is that it welcomes and respects the differences. In a multicultural and differentiated society, we must be extra clear and enshrine the common foundations. Values must cover children/students, staff and parents. We often agree on concepts such as respect, responsibility and communities, but we interpret them differently. This means that we must spend energy to jointly develop a framework for interpretation of valuation concepts. It is important to highlight the objectives of the concepts of values. Where there are many students with other languages, these languages should be written down. All values in work must be measurable and visible in behaviour.

\section{Operation}

It is every teacher's responsibility to develop and train the collective in everyday rituals that increase security and communities in a group. One way might be to schedule time for social training. Special programmes or materials are, for example: ART, Project Charlie and Vital Living. Discussions must constantly be about ethics and morality. Morality-ethics and civility will not develop by itself. It must be constantly updated on a daily basis.

A good way to get everyone to feel safe in a group is working with various drama and contact drills. An experience of role-play or trying to be another increases our imagination. Massage is another way of physical contact reducing destructive physical violence in the long term. Close physical contact builds empathy and respect for others. Theme works and projects on issues of values can also occur. Activities that increase the community at school/ preschool are important. Therefore, collections and recurring traditions are important. Sponsorship can be another way.

\section{Students' participation}

A local action plan for student empowerment and interaction should be prepared for each unit. Empowerment and responsibility should be given according to age and maturity in things related to mental and physical work. All classes/groups should have continuous scheduled class/ mentor/house-programmes. In each school there will be continually recurring student-counsels with strong links to the school management.

\section{Parental involvement}

A prerequisite to succeed fully with the preventive work in preschool, primary and secondary education is to collaborate with parents. Parental board, meetings, talks about the students' development, etc. will seize the parents' resources and knowledge. 


\section{Collaboration with actors outside the kindergarten and school}

We should work actively to create the network of social services, family counselling, child habilitation, leisure centres, police, church, clubs, childcare centres and psychiatry, other kindergartens and schools. In this way increases our chances of a good preventive work. Common education and information are activities that may generate many benefits for everyone. We also have joint premises in some parts of the organisation. Together with youth centres we work in networks.

\section{Competent staff}

Skills development for staff to invest in training around the issues of values is something that must be constantly recurring. The headmaster is responsible for adequate training given to employees to promote health.

\section{Information}

The local treatment plan's details have to be anchored among students, parents and staff. School officials are responsible for allowing time for training and to inform new employees. A primary worker/mentor/coach in class is responsible for making the action plan known among students and parents. The plan is presented in school catalogues and on the school website.

\section{Evaluation and follow-up}

In order to succeed at work with assessment and monitoring we must constantly evaluate and follow up what we do. To get a picture of the situation, we need to question students, parents and staff about what they feel and know. To support this work, we have developed an annual cycle for what and when we will evaluate the business. In order to get better, we need to focus on the possibilities for change and improvement. The annual quality statement evaluates the activities and new targets for the coming academic year.

\section{Summary}

Solenskolan has chosen diversity as its identity. The Swedish school authorities have drawn attention to this work and designated the school the best school in Sweden working for equal value 2008'. Student empowerment, child's needs and circumstances are fundamental in all contexts. Equal value and participation of all, both students and staff, is fundamental to the business. Different kinds of schools coexist under the same roof and collaborate across borders and the school has become a place which suits everyone. The Swedish and international laws on children's rights to education and a good working environment give strong support in the fight for all children's equal value. The municipality's treatment plan is an important tool in the quest to create a school where all can be equally involved. It is provided that the school should interact with parents, students and all other stakeholders in the community. This is comprehensive but important work in school.

Since Solenskolan was built in 1982, extensive work has been done to develop the influence and participation of children with disabilities or other origin. Today most students participate on their own merits in the majority of school activities. This school year, the school has chosen to work with the theme of communication. The theme focuses on knowledge and student empowerment and is an appropriate way to work across borders, regardless of age, ability or origin. Diversity is an asset and rich opportunity for everyone to learn and know the community. By exchanging experiences and activities with each other the students will be well prepared for the future. In fact, diversity is our strength. 


\section{References}

Antonovsky, A., \& Franke, A. (1997). Salutogenesis: The demystification of health. DGVT-Verlag, Tübingen.

Steinberg, J. Retrieved 18 August 2009 from http://www.ur.se/pedagog/Metod-och-inspiration/Ledarskap/ downloaded.

Strandberg, L. Retrieved 18 August 2009 from http:/ / translate.google.com/translate?hl=en\&sl=sv\&u=http:/ / www.friends.se / \&ei=n9SJSsu2IoHQsQP9hZHqAg\&sa=X\&oi=translate\&resnum=1\&ct=result\&prev=/ search $\% 3 \mathrm{Fq} \% 3 \mathrm{Dwww}$. friends.se $\% 26 \mathrm{hl} \% 3 \mathrm{Den} \% 26 \mathrm{client} \% 3 \mathrm{Dsafari} \% 26 \mathrm{rls} \% 3 \mathrm{Den}-\mathrm{us}$.

The Swedish Law on Safety and Health at Work. (1991). OHS Law: Act No. 677/91, amended 1977. Working Environment Act - Sweden [13178].

United Nations. (1989). United Nations Convention on the Rights of the Child. Retrieved 18 August 2009 from http: / / www2.ohchr.org/english/law/crc.htm.

For information about the school and its environs see the following websites:

www.spsm.se

www.friends.se

www.harnosand.se

www.miun.se 